\title{
O impacto da Pandemia no ensino de Língua Inglesa na Educação Inclusiva
}

\author{
The Impact of the Pandemic on English Language Teaching in Inclusive Education \\ El impacto de la pandemia en la enseñanza del idioma inglés en la educación inclusiva
}

Recebido: 12/06/2021 | Revisado: 20/06/2021 | Aceito: 21/06/2021 | Publicado: 05/07/2021

\author{
Gabriela de Souza Paim \\ ORCID: https://orcid.org/0000-0002-8215-3654 \\ Universidade Estácio de Sá, Brasil \\ E-mail: gabriela.spaim.3@gmail.com
}

\begin{abstract}
Resumo
Este artigo descreve como se lida com o ensino de língua inglesa em casa e remota com alunos especiais durante o período COVID-19. Empregando uma abordagem de pesquisa principalmente qualitativa, cinco pais com filhos diagnosticados com transtorno do espectro do autismo foram entrevistados online. Os dados foram submetidos à análise temática. Os resultados destacam os seguintes temas: (1) muitos são melhores do que um na educação em casa durante o isolamento; (2) das lutas com a transição para o cultivo de novas atividades; (3) nova realidade social em preparação para o período pós-pandêmico; (4) todas as formas de educação em casa são essenciais; e (5) famílias encorajando famílias nestes tempos difíceis. Este artigo fornece insights sobre a educação remota de crianças com autismo em meio à atual emergência global.
\end{abstract}

Palavras-chave: Educação domiciliar; Educação especial; L2; COVID-19.

\begin{abstract}
This article describes how to deal with home and remote English language teaching with special students during the COVID-19 period. Employing a primarily qualitative research approach, five parents with children diagnosed with autism spectrum disorder were interviewed online. Data were subjected to thematic analysis. The results highlight the following themes: (1) many are better than one at homeschooling during isolation; (2) struggles with the transition to cultivating new activities; (3) new social reality in preparation for the post-pandemic period; (4) all forms of home education are essential; and (5) families encouraging families in these difficult times. This article provides insights into the remote education of children with autism in the midst of the current global emergency.
\end{abstract}

Keywords: Home education; Special education; L2; COVID-19.

\section{Resumen}

Este artículo describe cómo lidiar con la enseñanza del idioma inglés en casa y a distancia con estudiantes especiales durante el período COVID-19. Empleando un enfoque de investigación principalmente cualitativo, se entrevistó en línea a cinco padres con hijos diagnosticados con trastorno del espectro autista. Los datos se sometieron a análisis temático. Los resultados destacan los siguientes temas: (1) muchos son mejores que uno en la educación en el hogar durante el aislamiento; (2) lucha con la transición para cultivar nuevas actividades; (3) nueva realidad social en preparación para el período pospandémico; (4) todas las formas de educación en el hogar son esenciales; y (5) familias animando a las familias en estos tiempos difíciles. Este artículo proporciona información sobre la educación remota de niños con autismo en medio de la actual emergencia mundial.

Palabras clave: Educación en el hogar; Educación especial; L2; COVID-19.

\section{Introdução}

Por causa do COVID-19, a maioria dos sistemas educacionais em todo o mundo fechou temporariamente. Os Direitos Humanos das Nações Unidas ${ }^{1}$ expressaram preocupação de que, embora a crise tenha ameaçado o acesso dos alunos à educação, as pessoas com deficiência, incluindo aquelas com autismo, são desproporcionalmente afetadas devido a restrições ecológicas que são reproduzidas na reação pandêmica. Como tal, esforços para melhorar as modalidades de educação domiciliar para

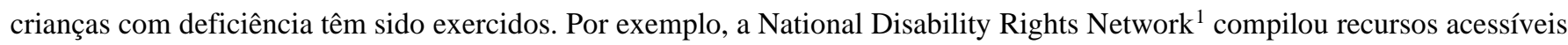
de estratégias instrucionais online em meio a interrupções nas escolas. Espera-se que ele ajude os pais a educar seus filhos com deficiências e, ao mesmo tempo, ficar em casa com segurança. 
A educação em casa, também conhecida como educação remota, é uma reforma educacional em todo o mundo, na qual os pais educam seus filhos em casa e em vários locais. Existem muitas razões pelas quais os pais preferem a educação em casa. Alguns não estão satisfeitos com as oportunidades educacionais atuais, enquanto outros acreditam que as crianças não estão ganhando vantagem com o arranjo escolar tradicional ${ }^{2}$. Observou-se a educação domiciliar como uma das modalidades emergentes de implementação educacional hoje. Também foi adotado por pais que têm filhos com deficiência. O número de crianças com deficiência recebendo instrução alternativa em casa aumentou significativamente

No Brasil, embora haja um desafio de fornecer um programa estruturado de educação em casa para cerca de cinco milhões de crianças com deficiência, relatou esforços de várias organizações e indivíduos para destacar a condição de um grupo vulnerável de crianças com deficiência em meio a a pandemia COVID-19. Houve uma chamada para reduzir os impactos da interrupção da escola por meio de métodos de escola em casa, como o aprendizado online. No entanto, tal abordagem teria sérias implicações para alguns pais cujas habilidades na educação em casa precisam ser melhoradas. Deve-se notar que programas estruturados de educação domiciliar para crianças com deficiência estão sendo desenvolvidos no país e principalmente por instituições privadas.

A demanda pelo aprendizado de línguas continua crescendo na era atual globalizada, o que torna o ensino e aprendizagem da língua inglesa de extrema importância. A investigação a respeito de métodos de aprendizado da língua estrangeira centra-se na área da linguística aplicada, onde muitas questões passam a ser analisadas, como a mediação do professor da língua, o número de horas disponíveis na disciplina, dentre outros fatores que interferem no processo de aprendizagem. Portanto, dadas as dificuldades no ensino de inglês no contexto nacional e atenção ao ensino de inglês no que diz respeito ao desenvolvimento de habilidades de linguagem oral e escrita, o presente estudo visa analisar o método chamado gamificação do ensino como estratégia de potencializar o aprendizado.

Cabe ressaltar inicialmente questões sobre ensino de línguas, posto que a comunicação se dá por meio de uma dimensão da alfabetização, e diante da universalidade da linguagem, esta enfrenta muitos desafios.

São notórios alguns obstáculos comuns aos processos de aprendizado da língua estrangeira, onde, no Brasil, tais matérias devem estar presentes no currículo escolar conforme a "Lei Guia e Base" (LDB), a partir do $5^{\circ}$ ano (6ªno) de escola pública. um primeiro ponto chama a atenção, tendo em vista que desde o primeiro ano de ensino se está incluído em muitas escolas particulares, mostrando um primeiro fator de disparidade e distanciamento do ensino em relação à classe social e questões de inclusão.

A eficácia da educação domiciliar para crianças com deficiência tem recebido atenção relativa nas pesquisas ${ }^{3}$. Além disso, estudos anteriores sobre educação domiciliar estruturada para crianças com deficiência, principalmente autismo, concentraram-se nos papéis dos pais. Um relatório está sendo desenvolvido atualmente, ressaltando a experiência de famílias que tiveram um membro com deficiência de desenvolvimento durante esta crise. Tirando ideias dos trabalhos acadêmicos mencionados, no entanto, experiências sobre o tipo informal de educação em remota para crianças com autismo durante a pandemia de COVID-19.

\section{Metodologia}

Este trabalho teve um desenho de pesquisa qualitativa. $\mathrm{Hogg}^{4}$ definiu a pesquisa qualitativa como 'um processo de investigação para compreender um problema social ou humano, com base na construção de uma imagem holística complexa, formada com palavras, relatando visões detalhadas de informantes e conduzida em um ambiente natural. Este desenho de pesquisa é considerado apropriado para atingir o objetivo do presente artigo, que é descrever a educação domiciliar de crianças com autismo. 
Além disso, esta pesquisa envolveu cinco pais de crianças portadoras de TEA como participantes. Eles foram selecionados por meio de uma combinação de técnicas de amostragem objetivas e convenientes. O principal critério considerado para a seleção é que os pais devem ter pelo menos um filho com diagnóstico de transtorno do espectro do autismo (TEA). Nove pais foram inicialmente contatados. No entanto, apenas cinco deles responderam positivamente em participar. O pesquisador obteve uma visão sobre como os pais educam seus filhos com autismo em casa por meio de procedimentos de entrevista. Devido às restrições da situação atual do COVID-19, as entrevistas pessoais não eram possíveis, portanto, um formulário ampliado denominado entrevista online foi conduzido individualmente com os participantes. A entrevista online é um método de pesquisa realizado por meio de comunicação mediada por computadores. Assim como a entrevista pessoal, a entrevista online normalmente pede aos participantes que descrevam o que pensam ou sentem sobre um aspecto.

Duas etapas de entrevistas online foram realizadas para este estudo. A primeira etapa envolveu um roteiro de entrevista contendo perguntas enviadas aos participantes por meio de chat online ou e-mail. As perguntas foram respondidas offline por uma semana, proporcionando aos participantes tempo suficiente em meio à sua agenda lotada. A segunda etapa envolveu o pesquisador em marcar um horário com cada participante para ser entrevistado ao vivo por meio de bate-papo online para esclarecer algumas respostas obtidas na primeira etapa.

Os dados obtidos nas entrevistas foram submetidos à análise temática. A análise temática é um processo sistemático de codificação, exame de significado e fornecimento de uma descrição da realidade social por meio da criação do tema. O pesquisador neste estudo examinou os códigos e interpretou-os em conceitos. Os conceitos semelhantes foram então agrupados em temas, estruturando os resultados para responder ao propósito declarado desta pesquisa. O tema é o principal produto desta análise de dados 5 .

\section{Resultados}

Com base na análise de códigos e conceitos extraídos das entrevistas, surgiram os seguintes temas sobre como os pais educam seus filhos com autismo em casa. Esses temas são descritos e discutidos a seguir.

\section{Tema 1: muitos são melhores do que um na educação em casa durante o isolamento}

A atual emergência pública reuniu familiares em casa por um longo período. Assim, no processo de educação domiciliar de crianças com autismo, a maioria dos membros da família estava envolvida ('Seu pai costuma cuidar bem dele, enquanto seu irmão às vezes intervém. Por outro lado, meu envolvimento como mãe acalma as situações durante os episódios de birra '- Pai C). Embora os serviços de terapia também sejam quase inacessíveis, os pais aproveitaram a modalidade online de intervenção ('A escola tradicional pode ser retomada em um bom tempo. Então, meu filho está fazendo terapia ocupacional online agora' Pai A).

Denen $^{6}$ enfatiza a importância do papel das famílias e dos consultores profissionais na educação domiciliar de crianças com autismo. No entanto, em meio à crise do COVID-19, Goldstein et al. ${ }^{7}$ expressou preocupação sobre o estresse inevitável que as famílias de crianças com autismo podem experimentar. Quando a maioria dos serviços sociais está sob demanda significativa nesses momentos, também há um desafio para o esforço coletivo das famílias para educar as crianças com autismo em casa.

\section{Tema 2: das lutas com a transição para o cultivo de novas atividades}

Os transtornos trazidos pela crise de saúde pública causaram mudanças drásticas na rotina das crianças com autismo. Conseqüentemente, eles tiveram que lutar até encontrar e se acostumar com as novas atividades em casa ('Ele tem um programa 
estruturado para o verão, mas não foi seguido por causa da condição pandêmica. Ele lutou para sobreviver. Mas, felizmente, agora ele conseguiu uma rotina de novas atividades e sem computador Pai D). Os pais também envolveram seus filhos com autismo em diferentes atividades em casa ('Asseguramos que ele participe de todas as atividades em nossa casa. Recentemente melhoramos nosso jardim. Ele ajudou a arrumar os tijolos internos' - Pai E).

Os pais empregam atividades de educação domiciliar diferentes e personalizadas. Ela citou que os pais têm um esforço extra para desenvolver atividades que eles acham que são as melhores para seus filhos. No contexto do surto global de COVID19, Liberali $^{2}$ ofereceu um guia para promover atividades para famílias e seus filhos com autismo. Ele discutiu os possíveis benefícios e estratégias especificamente das atividades físicas. Alguns exemplos de atividades físicas que podem ser realizadas são meditação, aula de exercícios online, jogos educativos e exercícios funcionais.

\section{Tema 3: nova realidade social em preparação para o período pós-pandêmico}

A pandemia trouxe muitas implicações sociais para famílias com crianças com autismo. Eles tiveram que ensinar novos insights sociais ('Eles não podem compreender facilmente o novo normal, então faço um esforço extra para deixá-los entender a situação. Um dia, permiti que ele dirigisse pela cidade e disse-lhe que quase todos os estabelecimentos estão próximos por causa de uma doença '- Pai E). Como medida de segurança, os pais também ensinaram aos filhos novos comportamentos sociais ('Eu tentei orientá-lo por que precisamos usar uma máscara. Eu moldei para ele e o treinei como usar uma quando sair' - Pai C).

O lar é o lugar onde começa a socialização e especialmente durante este período pandêmico. Embora haja uma preocupação geral sobre a restrição da educação em casa às interações sociais, a maioria dos pais está satisfeita com as oportunidades sociais oferecidas a seus filhos por meio dos serviços de educação em casa. Considerando os impactos sociais atuais do COVID-19, Liberali ${ }^{2}$ ofereceu dicas sobre como ensinar novas realidades sociais para crianças com autismo. Por exemplo, como crianças com autismo exibem uma gama de habilidades perceptivas em relação ao fenômeno, ele sugeriu que os pais, com a ajuda de terapeutas, precisam explicar concretamente as novas situações por meio de estratégias apropriadas, como mapas conceituais.

\section{Tema 4: todas as formas de educação em casa}

O surto global também tem sérios impactos nas decisões dos pais no que diz respeito às opções de modalidades educacionais para seus filhos com autismo. Parece que a educação em casa é uma das opções mais prováveis ('Não temos planos definidos no momento. No entanto, estamos certos de que não o enviaremos para a escola regular ou aulas online. Estamos considerando a educação em casa' - Pai B) . Embora a educação domiciliar estruturada seja difícil neste período de transição, os pais expressaram coletivamente que qualquer forma de educação que transpare dentro de suas casas é importante para o desenvolvimento de seus filhos ('Com uma criança com autismo em sua casa, paciência é um virtude. Eu ensino ao meu filho coisas básicas como cozinhar arroz, lavar pratos e varrer o chão. Este é o momento certo para aprender o essencial da vida '- Pai C).

Pimenta $^{8}$ ofereceu motivações para explicar por que a educação em casa é boa para crianças com autismo. Uma dessas motivações é que a educação em casa proporciona um aprendizado ideal. Dada a inevitável prática de distanciamento social como um novo normal no período quase pós-COVID-19, Relatou que muitos pais de crianças com deficiência estão considerando a educação em casa como um modo alternativo de educação. Apesar dos muitos desafios, os pais têm certeza de que, com apoio, podem ajudar seus filhos a atingir seu pleno potencial. 


\section{Tema 5: famílias incentivando famílias nestes tempos difíceis}

Uma família que tem uma criança com autismo faz parte de uma família maior de crianças com autismo. Os pais expressam preocupação com os serviços para outras crianças com autismo ("Acabei de ligar para seu terapeuta ocupacional porque estava preocupado com outras crianças com autismo que podem não ter acesso por causa do bloqueio" - Pai A). Outros pais oferecem dicas sobre como ensinar seus filhos com autismo a se adaptarem à nova situação ('Vamos ensinar nossos filhos a higienizar as mãos com frequência, evitar lugares lotados e beber muita água. Vamos aceitar a nova situação e fazer aproveite ao máximo '- Pai E).

Todos os tipos de incentivo de outras famílias e da comunidade são essenciais na educação doméstica para crianças com autismo. Quando há presença de incentivo entre as famílias, é mais provável que seja de outras famílias que vivenciam as mesmas experiências. No entanto, devido às restrições trazidas pela situação COVID-19, as famílias podem ficar sozinhas no manejo de seus filhos com autismo. Assim, Liberali ${ }^{2}$ sugeriu manter contato online com terapeutas, professores, cuidadores e outros pais para compartilhar e obter diferentes tipos de suporte necessários para a educação continuada de crianças com autismo de forma remota em período de pandemia de COVID-19.

\section{Discussão}

O COVID-19 exigiu uma rápida mudança para o ensino em ambientes virtuais em todo o espectro educacional. Nesse sentido, os instrutores que antes não estavam familiarizados, ou pouco familiarizados, com ambientes virtuais de ensino precisam aprender rápida e efetivamente como esses ambientes funcionam e como podem ser usados para ministrar cursos com sucesso, especialmente em contextos de formação de profissionais da saúde 9 .

A aprendizagem virtual é uma experiência de aprendizagem que é aprimorada por meio da utilização de computadores e da internet, tanto dentro quanto fora das instalações da organização educacional. A instrução geralmente ocorre em um ambiente online. As atividades de ensino são realizadas online, sendo o professor e os alunos fisicamente separados (em termos de local, horário ou ambos) $)^{10}$.

O cognitivismo enfoca o papel da mente e dos processos cognitivos na aprendizagem. Ele explica como o cérebro está funcionando e os níveis de desenvolvimento cognitivo que formam a base do aprendizado. Os estudos do cognitivismo ajudam os educadores a compreender como as pessoas aprendem e como ensinar de forma mais eficaz 9 .

$\mathrm{Na}$ aprendizagem virtual, o cognitivismo pode ser aplicado por meio de ambientes de aprendizagem personalizáveis, aplicativos de aprendizagem adaptativos e personalizados, IA, análises de aprendizagem, etc. É importante fornecer conteúdo que seja adequado às habilidades cognitivas de seus alunos, como texto, imagens, multimídia, etc., em que os alunos podem escolher como as aulas são apresentadas ${ }^{11}$.

O ensino e a aprendizagem são explicados como fenômenos sociais interativos complexos que ocorrem entre professores e alunos. As atividades de aprendizagem se concentram no compartilhamento de experiências, trabalho em equipe e aprendizagem colaborativa $^{12}$. O construtivismo social encontra aplicação perfeita em discussões em grupo, brainstorming, aprendizagem baseada em problemas e atividades em pequenos grupos. Um ótimo ambiente para esses tipos de atividades é a sala de aula virtual para ensino online ao vivo com ferramentas interativas como web conferência colaborativa, quadro branco online, salas de descanso, compartilhamento de tela, etc ${ }^{9}$.

A aprendizagem virtual tem muitas formas e termos relacionados. Eles parecem muito semelhantes, mas representam diferentes aspectos da aprendizagem e do ensino e podem nos ajudar a entender a essência da "aprendizagem virtual" ${ }^{12}$.

A aprendizagem virtual combina todos os termos mencionados acima. Ele pode superar muitas desvantagens do ambiente físico, como tempo, instalações, localização, etc. Os ambientes online permitem que os professores trabalhem com um 
número maior de alunos e otimizem suas tarefas de rotina. A aprendizagem virtual também traz novas técnicas pedagógicas às formas tradicionais de educação e torna a aprendizagem mais personalizada e conveniente ${ }^{13}$.

Em todo o país, os educadores estão sendo solicitados a ensinar alunos de todas as idades remotamente e a fornecer aos alunos oportunidades educacionais significativas e significativas, tudo sem colocar os pés no campus. Embora seja oferecido aos educadores desenvolvimento profissional na incorporação de tecnologia na sala de aula, a atual pandemia está pedindo aos professores que se adaptem mais rapidamente e com menos treinamento do que o esperado. Em face da mudança, os professores estarão à altura da ocasião para atender às necessidades em constante mudança de nossos alunos ${ }^{12}$.

Durante esse período em que os alunos não vão à escola, muitos podem ficar ansiosos ou lutar sem rotinas e procedimentos familiares. As rotinas fornecem estabilidade aos alunos e essa interrupção pode ter repercussões negativas. Como professor, o profissional pode ser sua verdadeira constante. Enquanto as portas da sala de aula estão fechadas, é importante tentar ser o mais consistente possível. Isso pode exigir o estabelecimento de novas rotinas. O mais importante é manter uma conexão positiva com seus alunos. Um ótimo ponto de partida é fazer ligações para os pais dos alunos em sua sala de aula ${ }^{14}$.

Levando em consideração todos os apontamentos que evidenciam o papel social exercido pela escola enquanto um lugar propício para a formação e o desenvolvimento humano, faz-se necessário contextualizar a importância do ensino-aprendizagem da língua inglesa nesse contexto, bem como sua contribuição para o processo educacional como um todo, indo muito além da aquisição de um conjunto de habilidades linguísticas.

Assim, a proposta de ensino que integra as línguas estrangeiras no currículo da educação regular e pública fundamentase na valorização da natureza interacionista e sociodiscursiva da linguagem, ou seja, no reconhecimento da oralidade como objeto de ensino. Ao mesmo tempo em que privilegia práticas de uso da linguagem de maneira a capacitar o estudante a se comunicar com o mundo ${ }^{15}$.

Nesse sentido, o ensino de Língua Inglesa na escola regular é de suma importância para:

estender o horizonte de comunicação do aprendiz para além de sua comunidade linguística restrita própria, ou seja, fazer com que ele entenda que há uma heterogeneidade no uso de qualquer linguagem, heterogeneidade esta contextual, social, cultural e histórica. Com isso, é importante fazer com que o aluno entenda que, em determinados contextos (formais, informais, oficiais, religiosos, etc.), em determinados momentos históricos (no passado longínquo, poucos anos atrás, no presente), em outras comunidades (em seu próprio bairro, em sua própria cidade, em seu país, como em outros países), pessoas pertencentes a grupos diferentes em contextos diferentes comunicam-se de formas variadas e diferentes ${ }^{16}$

Além disso, não se pode ignorar que com os inúmeros avanços tecnológicos alcançados nas últimas décadas, a democratização do uso da internet e outras características da globalização, percebe-se o contato direto com a cultura de língua inglesa, atualmente disseminada pelo mundo através dos meios de comunicação e das formas de entretenimento, como músicas, seriados e filmes, etc., que contribuem para o domínio do idioma no mundo.

Sobre este assunto, Oliveira ${ }^{15}$, aponta que ao estudar uma Língua estrangeira:

o estudante entra em contato com outra cultura, o que contribui para que ele conheça aspectos culturais diferentes daqueles presentes na sua comunidade. Isso pode levar o estudante a um processo de reflexão acerca do outro e de si próprio.

Nessa perspectiva, é válido mencionar a importância dos chamados Parâmetros Curriculares Nacionais (PCN), que também afirmam que a aprendizagem de uma língua estrangeira é uma possibilidade de aumentar as possibilidades de interação, além de auxiliar o aluno no seu desenvolvimento pessoal e profissional.

Nesse sentido, destaca-se a disposição do PCN que compreende na: 
aprendizagem de Língua Estrangeira uma possibilidade de aumentar a autopercepção do aluno como ser humano e como cidadão. Por esse motivo, ela deve centrar-se no engajamento discursivo do aprendiz, ou seja, em sua capacidade de se engajar e engajar outros no discurso de modo a poder agir no mundo social ${ }^{17}$.

Historicamente, a inclusão de uma Língua Estrangeira no currículo escolar no Brasil se deu em 1808 com a chegada da família real portuguesa, sendo que, até 1889, depois da proclamação da República, o inglês ainda possuía caráter opcional no ensino regular. Somente ao final do século XIX foi que essa língua se tornou obrigatória no currículo escolar brasileiro ${ }^{18}$.

Em 1961, a LDB vigente retirou a obrigatoriedade do ensino de Língua Estrangeira, deixando a cargo dos governos estaduais a sua inclusão ou não nas séries do ginásio. Com o advento da Resolução no 58 de 1976, o Ministério da Educação retoma a obrigatoriedade do inglês como LE no colegial. E em 1996, com a retificação da LDB, a partir da Lei nº 9.394/96, a LE torna-se obrigatória a partir da quinta série. Três anos depois, com a publicação dos PCNs voltados para o ensino fundamental, passa-se a valorizar os objetivos dessa disciplina no currículo, apresentando assim uma abordagem voltada ao sociointeracionismo cultural ${ }^{18}$.

Segundo dados do Ministério da Educação, em 1999 foi publicada uma edição dos PCNEM voltada para o Ensino Médio, que já destacava uma visão mais ampliada sobre as atribuições do novo modelo de ensino, propondo uma reforma curricular, a partir da divisão do conhecimento escolar em três grandes áreas: Linguagens, Códigos e suas Tecnologias; Ciências da Natureza; Matemática e suas Tecnologias; e Ciências Humanas e suas Tecnologias.

Dessa maneira, busca-se desenvolver no aluno a apercepção de variadas linguagens, de modo a utilizá-las em diferentes situações e contextos. Além disso, a tecnologia permite uma maior integração destes saberes, de forma que, a partir dos anos 2000, com o PCN+, a ênfase na interdisciplinaridade das áreas de conhecimento na escola regular ficou ainda mais visível.

Nesse contexto, a inclusão de uma LE no currículo escolar possui um fator histórico que faz referência ao papel hegemônico da língua, interligando fatores relativos à integração entre linguagens de uma comunidade local com a convivência com outras culturas estrangeiras, imigrantes, indígenas, entre outras possibilidades do mundo globalizado. Assim, pode-se dizer que em nosso país, leva-se em consideração, principalmente, os fatores históricos e o socioeconômico ao adotar o Inglês como LE no currículo das escolas públicas.

A globalização estreitou os espaços geográficos como conhecíamos até então e fez com que o encontro entre pessoas de países e identidades diferentes se tornasse mais fácil, e para tanto uma língua comum foi estabelecida: o inglês. E não foi por acaso a escolha dessa língua; em outros tempos o latim e o francês foram línguas usadas amplamente, entretanto não tiveram a mesma expansão que a língua inglesa, por um lado devido a motivos econômicos e sociais, primeiro pela colonização inglesa e depois pelo império econômico americano e outro foi o avanço tecnológico, o qual fez com que o inglês rapidamente se espalhasse pelo mundo ${ }^{18,19}$.

Nessa perspectiva, o aprendizado de uma LE constitui-se em mais do que uma simples obrigação, pelo contrário, é parte constituinte desse processo de integração mundial. Sobre o assunto, Oliveira ${ }^{20}$ aponta que o inglês se trata de "um componente essencial para educação básica dos brasileiros e precisa ser considerada como uma área de conhecimento tão importante tanto quanto outra qualquer".

Em outras palavras, a disciplina de inglês não deve ser ofertada nas escolas de Ensino Fundamental e Médio no Brasil apenas pelo fato de se trata-se de uma exigência do Ministério da Educação, ou ainda mera formalidade dos currículos escolares, uma vez que esse idioma contribui para a formação plena do indivíduo que a domina.

Nesse sentido, os PCNs de $\mathrm{LE}^{17}$ consideram que o aprendizado de uma outra língua se trata de uma atividade indispensável para se ter um acesso igualitário ao mundo dos negócios, à tecnologia, e consequentemente ao mercado de trabalho. 
Além disso, "O ensino de uma Língua Estrangeira na Escola tem papel importante à medida que permite aos alunos entrar em contato com outras culturas, com modos diferentes de ver e interpretar a realidade" ${ }^{17}$.

Diante disso, os alunos e educadores devem compreender a entendimento de que, ao conhecer e aprender uma LE, aproxima-se também de sua cultura, sua identidade, sem, contudo, desvalorizar nossa própria língua, símbolo da identidade nacional, e principalmente sem abrir mão de seus valores. O ensino de língua inglesa deve, portanto, ser proposto através da construção de espaços e práticas que promovam a integração dos saberes, inclusive com os demais componentes do currículo, contextualizando o conhecimento adquirido através de uma perspectiva do acesso à cultura estrangeira como instrumento de expansão da aprendizagem.

\section{Conclusão}

Este artigo descreve como se dá a educação remota em alunos com autismo em meio à situação do COVID-19. Os resultados ressaltam os seguintes temas: (1) muitos são melhores do que um na educação em casa durante o isolamento; (2) das lutas com a transição para o cultivo de novas atividades; (3) nova realidade social em preparação para o período pós-pandêmico; (4) todas as formas de educação em casa são essenciais; e (5) famílias encorajando famílias nestes tempos difíceis. Embora restrito a um determinado contexto e pequena amostra, este trabalho apresenta um vislumbre da educação domiciliar de crianças especiais em meio aos impactos da atual crise global.

Diante de tudo que foi exposto neste trabalho, pode-se afirmar que, é constante e cada vez mais relevante o papel exercido pela escola no âmbito social, político, entre outros de importância para a interação do indivíduo na sociedade.

Como sugestão para trabalhos futuros, constitui-se a carência de mudanças nos PCNs, organizando melhor a grade curricular em um período pós-pandêmico. O contexto atual trouxe a reflexão sobre como lidar com alunos que possuem necessidades educacionais especiais, a importancia da LE para o desenvolvimeto cultural do discente e o avanço tecnológico nas escolas em um ensino remoto.

\section{Referências}

Brasil. (2006). Ministério da Educação e do Desporto. OCEM - Orientações Curriculares para o Ensino Médio: Linguagens, Códigos e suas Tecnologias. Brasília: Ministério da Educação.

Brasil. (1998). Ministério da Educação e do Desporto. Secretaria de Educação Fundamental. Parâmetros curriculares nacionais terceiro e quarto ciclos do ensino fundamental: introdução aos parâmetros curriculares nacionais. MEC/SEF.

Bronckart, J.P. (2006) Atividade de linguagem, discurso e desenvolvimento humano. In: Machado, A. R., Matencio, M. I. M. (Orgs.). Mercado de Letras.

Fisher, Graciana Simoní. (2001). Um ambiente virtual multimídia de ensino na WEB, com transmissão ao vivo e interatividade.

Dellagnelo, L. G. V. Tecnologia para promover qualidade e equidade na educação básica. In:_. Carvalho, M. E. G. (Org.), Diálogos sobre a Educação - $3^{\text {a }}$ CONAE - Brasília, 2018/ Fórum Nacional de Educação (FNE), p. 33-42.

Dennen, V. (2020, March 13). Teaching Online During COVID-19. Vanessa Dennen. https:// vanessadennen.com/teaching-online-during-covid-19/

Goldstein, D, Popescu, A. \& Hannah-Jones, N. (2020, April 6). As School Moves Online, Many Students Stay Logged Out. The New York Times. https://www.nytimes.com/2020/04/06/ us/coronavírus-schools-attendance-absent.html

Hogg, L. (2017) Funds of knowledge: an investigation of coherence within the literature. Teaching and Teacher Education, 27, 666-677, 2011, Liberalli, F. C. Analyzing classroom dialogue to create changes in school. Learning and instruction, 48, 66-69.

Jordão, Tereza. C. (2009). Formação de educadores: a formação do professor para a educação em um mundo digital. In: Portal Do Professor, 2009, TECNOLOGIAS DIGITAIS NA EDUCAÇÃO. P. 9-17. <http://portaldoprofessor.mec.gov.br/storage/materiais/0000012178.pdf>.

Kalva, Júlia Margarida \& Ferreira, Aparecida de Jesus. O livro didático e as representações de identidade nacional: uma reflexão acerca da construção da identidade em alunos e professores de inglês. Palhoça, Santa Catarina.

Kenski, Vani. M. Tecnologias e ensino presencial e a distância. http://<https://books.google.com.br/books?id=WHeADwAAQBAJ\&hl=ptBR\&source=gbs_book_other_versions $>$. 
Research, Society and Development, v. 10, n. 8, e6710817118, 2021

(CC BY 4.0) | ISSN 2525-3409 | DOI: http://dx.doi.org/10.33448/rsd-v10i8.17118

Liberali, F. C. (2018). Formação Crítica de Educadores: Questões Fundamentais. Pontes Editores, (4a ed.).

Lima, Diógenes Cândido. (2009). Preconceito contra o ensino de língua estrangeira na rede pública. In. Ensino e aprendizagem de língua inglesa: conversas com especialistas. Editora: Parábola.

Lopes, Diana Vasconcelos. (2012). As novas tecnologias e o ensino de línguas estrangeiras. Revista Científica Tecnologus. ASBRATEC, Edição 06

Magalhães, M. C. C. Escolhas teórico-metodológicas em pesquisas com formação de professores: as relações colaborativo-críticas na constituição de educadores.

Mateus, E. \& Oliveira, N. B. (Org.). (2014). Estudos Críticos da linguagem e formação de professores/as de línguas. Pontes, 17-48.

Oliveira, L. A. (2009). Ensino de línguas estrangeiras para jovens e adultos na escola pública. In: Lima, D. C. de (ed.). Ensino e aprendizagem de língua inglesa: conversas com especialistas. p. 21-30. Parábola Editorial.

Pimenta, S. G. (2005). O estágio na formação de professores: unidade teórica e prática. (3a ed.), Cortez, [1994].

Rodrigues, Carlos Rangel et al. (2008). Ambiente virtual: ainda uma proposta para o ensino. Ciências \& Cognição, $13,-83$.

UNESCO. 2020. (Organização das Nações Unidas para a Educação, a Ciência e a Cultura). Suspensão das aulas e resposta à COVID-19. https://pt.unesco.org/covid19/educationresponse. 